www.jmscr.igmpublication.org

Impact Factor 3.79

Index Copernicus Value: 5.88

ISSN (e)-2347-176x ISSN (p) 2455-0450

crossref DOI: http://dx.doi.org/10.18535/jmscr/v4i1.30

Journal Of Medical Science And Clinical Research

\title{
New Onset Diabetes after Renal Transplantation (NODAT): Prevalence, Risk Factors and Treatment
}

$\underline{\text { (Original article) }}$

\author{
Authors \\ Lakshminarayana GR ${ }^{1}$, Sheetal LG $^{2}$, Anil $M^{3}$, Rajesh $R^{4}$, George $K^{5}$, Unni VN \\ ${ }^{1}$ Consultant Nephrologist, Department of Nephrology, EMS Memorial Cooperative Hospital and Research \\ Centre, Perinthalmanna, Malappuram, Kerala \\ ${ }^{2}$ Associate Professor, Dept of Physiology, MES Medical College, Perinthalmanna, Malappuram, Kerala, \\ ${ }^{3}$ Professor, Dept of Nephrology, Amrita Institute of Medical Sciences and Research Centre, Kochi, Kerala \\ ${ }^{4}$ Professor, Dept of Nephrology, Amrita Institute of Medical Sciences and Research Centre, Kochi, Kerala \\ ${ }^{5}$ Professor and Head, Dept of Nephrology, Amrita Institute of Medical Sciences and Research Centre, Kochi, \\ Kerala \\ ${ }^{6}$ Senior Consultant, Nephrology, CoE Nephrology and Urology, Aster Medicity, Kochi, Kerala \\ Corresponding Author

\section{Dr Lakshminarayana GR}

Consultant Nephrologist, Department of Nephrology, EMS Memorial Cooperative Hospital and Research

Centre, Perinthalmanna, Malappuram, Kerala, India-679322

Email: drlng23@gmail.com, Phone: (+91) 9495161833

\begin{abstract}
Background: This study was conducted to assess the prevalence rate, risk factors and response to treatment of NODAT after renal transplantation.

Methods: All consecutive non-diabetic renal transplant recipients (RTR) from 2005 to 2011; done at AIMS, Kochi, were included in the study. ADA criteria (2003) for NODAT was for its diagnosis.

Results: The study group included 125 (M:101, F:24) RTRs with a mean age of 31.53 years, with a mean follow-up of 32.01 months after surgery. The prevalence rate of NODAT was 23\%. Majority (80 \%) of recipients with NODAT, had it within first 6 months after surgery. The prevalence rate of NODAT was higher males and those aged $>40$ years. The prevalence rate of NODAT was higher in those with family history of diabetes mellitus and pre-transplant impaired glucose levels. The prevalence rate of NODAT was higher with Tacrolimus based regimen and also those receiving methyl prednisolone as part of antirejection therapy. Majority (55\%) of those with NODAT had normal BMI. The prevalence of graft dysfunction was higher in those with NODAT.

Conclusions: The prevalence rate of NODAT was 23\%, with a peak incidence in initial 6 months after renal transplantation. The non-modifiable risk factors for NODAT were; age > 40 years, male gender, pretransplant impaired glucose levels and family history of diabetes mellitus. The modifiable risk factors for NODAT were; immunosuppressive drugs (Tacrolimus > Cyclosporine A), antirejection therapy with Methyl prednisolone. The prevalence of graft dysfunction was higher in those with NODAT than those without NODAT.

Key Words: NODAT, Renal transplantation, Modifiable risk factors, non-modifiable risk factors,
\end{abstract}




\section{Introduction}

New-onset diabetes after transplantation [NODAT] is a well-recognized complication of organ transplantation especially after solid organ transplantation with occurrence at different posttransplant intervals. The NODAT shown to affect both the patient and renal allograft survival. The reported prevalence rate of NODAT varies widely $(2-53 \%)$ in literature, based on the diagnostic criteria and immunosuppressive protocols. [1-9] The prevalence rate of NODAT in Indian studies varied from $4.8-21.4 \%{ }^{[10-13]}$ The risk factors of NODAT are classified as non-modifiable (age, gender, ethnicity, family history of diabetes mellitus), modifiable or potentially modifiable (immunosuppressive medications, life style, impaired glucose tolerance test, dyslipidaemia, $\mathrm{HCV}$ or CMV infection); the former helps to facilitate the identification of high risk individuals, and the latter two helps to optimize the management of NODAT. ${ }^{[14-22]}$ The recommended treatment for NODAT is similar to type 2 diabetes mellitus; OHA, Insulin, education regarding diabetes and life style modification. ${ }^{[22-}$ ${ }^{25]}$ The present study was conducted to assess the prevalence rate, risk factors and response to treatment of NODAT in live related renal recipients (RTR).

\section{Aims and Objectives}

1. To study the prevalence rate of NODAT and

2. To identify the risk factors for NODAT and response to therapy

\section{Materials and Methods}

All consecutive renal allograft recipients (live related donor) who underwent renal transplantation at Amrita Institute of Medical Sciences and Research Centre, Kochi, from 2005 to 2011. Subjects with diabetes mellitus prior to renal transplantation were excluded.

\section{Diagnosis of NODAT}

The International Consensus Guidelines (2003) on New-Onset Diabetes after Transplantation recommended that the diagnosis of NODAT be based on the American Diabetes Association criteria for the diagnosis of diabetes. ${ }^{[26]}$ Accordingly, NODAT is diagnosed by finding two fasting plasma glucose (FPG) values (measured on different days) higher than 126 $\mathrm{mg} / \mathrm{dl}$; a plasma glucose level higher than 200 $\mathrm{mg} / \mathrm{dl}$ at $2 \mathrm{~h}$ during a 75 -g oral glucose tolerance test (OGTT) a random plasma glucose level higher than $200 \mathrm{mg} / \mathrm{dl}$ in a patient with typical diabetes clinical manifestations or A1C more than $6.5 \%$.

\section{Statistical Analysis}

Mean \pm standard deviation (SD) and percentages were used for summarizing the data. The variables were analysed by univariate and multivariate analysis to assess their significance. The primary endpoint of the analysis was occurrence of NODAT. The confidence interval (CI) was $95 \%$ and a $P<0.05$ was used for statistical significance. All statistical analyses were performed with SPSS version 17.0 and Analyse-it (®) for Windows.

\section{Results}

This retrospective study included 125 consecutive nondiabetic RTRs (Males:101, Females:24) of age 11-55 years (Mean:31.52, SD:9.43), with followup of 3-69 months (mean:32.01, SD:18.74) after transplantation. None of the subjects had $\mathrm{HCV}$ or HBV or HIV infection. The demographic parameters of the subjects are summarised in table 1.

\section{Prevalence of NODAT and its risk factors}

$29(23 \%)$ subjects were diagnosed to have NODAT as per ADA criteria over follow-up of 3 - 69 months (Mean:31.52, SD:9.43).Majority (80 $\%$ ) of recipients with NODAT, had it within first 6 months, suggesting peaking of incidence of NODAT in first 6 months after renal 
transplantation. Subjects with age more than 40 years, had higher prevalence $(31.52 \%$ Vs 21.70 $\%)$ of NODAT. The mean age of patients with NODAT higher (39.69 years) than those without (29.99 years) NODAT (table 2).Males formed majority $(86.20 \%)$ of subjects with NODAT (table 3).The prevalence rate of NODAT was higher in males than females (24.7 Vs $16.67 \%$ ) (table 3). Majority (59\%) of those with NODAT had family history of diabetes mellitus suggesting a higher predisposition (table 3).Pre-transplant impaired glucose levels were found in $21.6 \%$ (27) of subjects; $48 \%$ of them (13/27) were diagnosed to have NODAT after surgery (Table 3 ).

All RTRs received standard triple immunosuppression in addition to antihypertensives and supportive management. The immunesuppressives were in the form of Cyclosporine A $5 \mathrm{mg} / \mathrm{kg} /$ day in two divided doses, Mycophenolate Mofetil (MMF) 750 to $1000 \mathrm{mg}$ twice daily and injection methyl prednisolone 500 $\mathrm{mg}$ was administered before the release of vascular clamps followed by prednisolone $0.5 \mathrm{mg}$ per $\mathrm{kg}$ per $\mathrm{kg}$ daily post op day 1.Induction therapy was given in patients with high immunological risk (spousal donors) with interleukin 2 receptor antagonists (Daclizumab or Basiliximab). The Tacrolimus instead of Cyclosporine A was started in spousal donor recipients and young girls. None of subjects received steroids or CNI sparing regimen. The dose of prednisolone was tapered to by $0.3 \mathrm{mg} / \mathrm{kg}$ body weight orally during 3 months, gradually tapered to $7.5 \mathrm{mg}$ /day over period of 6 months. None of the subjects in the study received CMV prophylaxis; however, they were evaluated for it, if any appropriate indications. The MMF was changed to Azathioprine if stable graft function without any episodes of graft rejections at end of 6 months in selected cases if subjects have financial difficulties.

The prevalence rate of NODAT was higher in those on Tacrolimus (45\% or 5 out of 11 ) than those on Cyclosporine A $(21.05 \%, 24$ out of 114).
$22.4 \%$ (28 out of 125) subjects had episodes of acute rejections during the study period and was treated with antirejection therapy as per the protocol. The prevalence rate of NODAT was higher $(28.57 \%, 8$ out of 28$)$ in subjects receiving methyl prednisolone as part of antirejection therapy than those who did not have rejections $(21.65 \%, 21$ out of 97$)$. Antirejection therapy was the main reason for administering extra steroids.

Majority (55\%) of those with NODAT had normal BMI and $28 \%$ were overweight, $14 \%$ were underweight and only $3 \%$ were having obesity, suggesting that Indians are predisposed to NODAT even with normal BMI. There was no statistically significant difference in BMI in those with and without NODAT (table 2).

\section{Treatment of NODAT}

Majority (58.62 \%, 17 out of 29) of subjects with NODAT were treated with oral hypoglycemic agents (OHA) along with diet \& life style modification. The $20.69 \%$ (6 out of 29) of subjects were treated with combination of Insulin and OHA and additional $20.69 \%$ (6 out of 29) were managed with Insulin. The $10.34 \%$ (3 out of 29) of subjects responded to diet \& life style modification.

\section{Effect of NODAT on graft function}

Those with serum creatinine level $>1.4 \mathrm{mg} / \mathrm{dl}$, or rise in serum creatinine of $30 \%$ from the baseline were considered to have graft dysfunction. The prevalence of graft dysfunction was higher in those with NODAT $(48.28 \%, 14$ out of 29$)$ than those without NODAT $(39.17 \%, 38$ out of 97$)$. 


\begin{tabular}{|l|c|c|c|c|}
\hline Table 1: Descriptive characteristics of study population \\
\hline & Minimum & Maximum & Mean & Std. Deviation \\
\hline Age (years) & 11 & 55 & 31.53 & 9.43 \\
\hline Sr. Creatinine (mg/dl) & 0.5 & 4.2 & 1.48 & 0.58 \\
\hline $\begin{array}{l}\text { Time after Transplantation } \\
\text { (months) }\end{array}$ & 03 & 69 & 32.01 & 18.74 \\
\hline BMI (kg/m2) & 11 & 33 & 20.98 & 3.13 \\
\hline
\end{tabular}

\begin{tabular}{|l|c|c|c|}
\hline Table 2: Characteristics of subjects with and without NODAT \\
\hline Parameter & $\begin{array}{c}\text { With NODAT } \\
\text { (Mean } \pm \text { SD) }\end{array}$ & $\begin{array}{c}\text { Without NODAT } \\
\text { (Mean } \pm \text { SD) }\end{array}$ & (p-value) \\
\hline Age $($ years) & $36.69 \pm 7.98$ & $29.99 \pm 9.36$ & 0.001 \\
\hline Sr. Creatinine $(\mathbf{m g} / \mathbf{d l})$ & $1.45 \pm 0.58$ & $1.59 \pm 0.58$ & 0.253 \\
\hline BMI prior to TX $(\mathbf{k g} / \mathbf{m} 2)$ & $20.71 \pm 3.23$ & $21.74 \pm 2.63$ & 0.12 \\
\hline BMI after to $\mathbf{T X}(\mathbf{k g} / \mathbf{m} 2)$ & $22.01 \pm 3.12$ & $23.33 \pm 3.28$ & 0.051 \\
\hline
\end{tabular}

\begin{tabular}{|c|c|c|c|}
\hline Parameter & $\begin{array}{c}\text { Subjects with NODAT } \\
N=29 \text { out of } 125(23 \%)\end{array}$ & $\begin{array}{c}\text { Subjects without NODAT, } \\
\mathrm{N}=96 \text { out of } 125(77 \%)\end{array}$ & $\begin{array}{c}\text { Univariate } \\
\text { analysis (p-value) }\end{array}$ \\
\hline Age $<40$ years & 23 & 83 & \multirow[t]{2}{*}{0.011} \\
\hline Age $>40$ years & 6 & 13 & \\
\hline Males & 25 & 76 & \multirow[t]{2}{*}{002} \\
\hline Females & 4 & 20 & \\
\hline $\begin{array}{l}\text { Positive family history of } \\
\text { DM }\end{array}$ & 17 & 12 & 0.02 \\
\hline Pre-transplant IGT & 13 & 14 & 0.01 \\
\hline $\begin{array}{l}\text { ART prior to } \\
\text { development of NODAT }\end{array}$ & 8 & 20 & 0.03 \\
\hline
\end{tabular}

\section{Discussion}

New-onset diabetes after transplantation [NODAT] is a well-recognized complication after renal transplantation affecting both the patient and renal allograft survival, with varying prevalence rates in India. ${ }^{[10-13]}$ Our study included 125 RTRs, with mean age of 31.52 years, with mean followup of 32.01 months after transplantation. The males formed majority $(80.8 \%$ ) of the RTRs; male: female of 4.2:1. The demographic profile of subjects was similar to other Indian studies. ${ }^{[10,11]}$
The prevalence rate of NODAT in study was $23 \%$ as per ADA criteria ${ }^{[26}$ ] The peak incidence of NODAT was seen in initial 6 months after renal transplantation. The prevalence of NODAT was higher $(31.52 \%)$ in subjects with age of $>40$ years. The prevalence rate of NODAT was higher in males $(24.7 \%)$ than females $(16.67 \%)$. Majority (59\%) of those with NODAT had family history of diabetes mellitus. The prevalence rate of NODAT was higher (48\%)in subjects with pretransplant impaired glucose levels. Hence, age > 40 years, male gender, pre-transplant impaired 
glucose levels and family history of diabetes mellitus were the non-modifiable risk factors for NODAT in our study; consistent with other reported literature. [1-5,8-11, 19, 20, 22] $^{-1}$

The type of immunosuppressive regimen accounts for the variability in incidence and prevalence rates of NODAT between studies. Both corticosteroids and Calcinurin inhibitors are diabetogenic by multiple mechanisms. ${ }^{[2,4,}{ }^{16]}$ In our study the prevalence rate of NODAT was higher $(45 \%)$ in subjects on Tacrolimus based regimen than those with Cyclosporine A containing immunosuppressive therapies $(21.05 \%)$. None of subjects received CNI or Steroid free regimen. $22.4 \%$ subjects had episodes of acute rejections during the study period and was treated with antirejection therapy as per the protocol. The prevalence rate of NODAT was higher $(28.57 \%$,) in subjects receiving methyl prednisolone as part of antirejection therapy than those who did not have rejections (21.65\%). The higher prevalence of NODAT with Tacrolimus than Cyclosporine A based regime in our study is

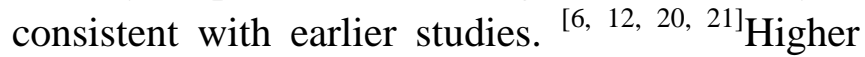
incidence and prevalence rates of NODAT in relation to antirejection therapy with Methyl prednisolone is also consistent other earlier reports. ${ }^{[11]}$

Majority (55 \%) of those with NODAT had normal BMI and $28 \%$ were overweight, $14 \%$ were underweight and only $3 \%$ were having obesity, suggesting that Indians are predisposed to NODAT even with normal BMI, suggesting that subjects of Asian origin may have genetic predisposition to NODAT as reported in earlier studies. ${ }^{[20,21]}$

\section{Treatment of NODAT}

The treatment advised for NODAT is similar to that for type 2 diabetes mellitus. ${ }^{[11,22]}$ In our study majority $(58.62 \%)$ of subjects responded adequately to oral hypoglycemic agents (OHAMetformin, Glibenclamide, Gliclazide, Glimepiride) along with diet\& life style modification. The $20.69 \%$ of subjects needed combination of Insulin and OHA and additional $20.69 \%$ were managed with Insulin alone. The $10.34 \%$ of subjects responded to only diet \&life style modification. Although; OHA are effective, their use could alter immunosuppressive drug levels due to competition for common cytochrome P-450 pathway or altered GI motility, their use should be carefully monitored. ${ }^{[11,22]}$

\section{Effect of NODAT on graft function}

The prevalence of graft dysfunction was higher in those with NODAT $(48.28 \%)$ than those without NODAT $(39.17 \%)$ in our study. The NODAT is a major risk factor for cardiovascular disease and mortality as well as associated with adverse impact on graft survival and graft loss rate of infections and increased health care costs. ${ }^{[1,2,3]}$

\section{Limitations:}

1) Effect of $\mathrm{HCV}$ and $\mathrm{CMV}$ infection were not assessed as none of the patients had HCV infection and CMV titers were not monitored routinely, except in cases with suspicion of CMV infection. 2) The therapeutic drug monitoring of CNI or MMF was not done due to financial constraints. 3) HLA matching status of recipient with the donor and its effect on NODAT was not assessed. 4) Effect of NODAT on cardiovascular disease was not assessed.

\section{Conclusions}

The prevalence rate of NODAT in study was $23 \%$, with a peak incidence in initial 6 months after renal transplantation. The age $>40$ years, male gender, pre-transplant impaired glucose levels and family history of diabetes mellitus were the nonmodifiable risk factors for NODAT in our study. The modifiable risk factors contributing to higher prevalence of NODAT included, immunesuppressive drugs (Tacrolimus > Cyclosporine A), antirejection therapy with Methyl prednisolone. Majority of those with NODAT had normal BMI and only minority were obese. Majority of the subjects responded to oral hypoglycemic agents (OHA-Metformin, Glibenclamide, Gliclazide, 
Glimepiride) along with diet \& life style modification. The prevalence of graft dysfunction was higher in those with NODAT than those without NODAT.

\section{Source(s) of support: Nil \\ Conflicts of Interest: Nil}

\section{References}

1. Victor MM, Ananda B, Patricia JE, Jorge AV, Erwin JA, Sherine EG, et al. Posttransplantation Diabetes. A systematic review of the literature. Diabetes Care 2002; 25:583-592.

2. Maskey R. New-Onset Diabetes After Transplant (NODAT). J Diabetes Res Ther 2105, 1(1): DOI: Http:// Dx.Doi.Org/10.16966/2380-5544.105.

3. Marília BG, Roberta AC. Post-Transplant Diabetes Mellitus. Diabetology \& Metabolic Syndrome 2009, 1:1-4. DOI:10.1186/1758-5996-1-14.

4. Emilio R, Gema FF, Rosalia V, Juan CR, Celestino P, Rosa P, et al. New-Onset Diabetes After Kidney Transplantation: Risk Factors. J Am SocNephrol 2006; 17: S291-S295.

DOI: 10.1681/Asn.2006080929.

5. Mazali FC, Lalli CA, Alves-Filho G, Mazzali M. Post-transplant diabetes mellitus: incidence and risk factors. Transplant Proc. 2008; 40(3):764-766. DOI: 10.1016/j.transproceed.2008.03.018.

6. Gnatta D, Keitel E, Heineck I, Cardoso BD, Rodrigues AP, Michel K, et al. Use of tacrolimus and the development of posttransplant diabetes mellitus: A Brazilian single-center, observational study. Transplant Proc. 2010;42(2):475-478. DOI: 10.1016/j.transproceed.2010.02.021.

7. First MR, Gerber DA, Hariharan S, Kaufman DB, Shapiro R. Post-transplant diabetes mellitus in kidney allograft recipients: incidence, risk factors, and management. Transplantation. 2002; 73(3): 379-386.

8. Fernando GC, Todd EP, Kwame O, Mitchell LH, Ronald MF.Post-Transplant Diabetes Mellitus: Increasing Incidence in RenalAllograft Recipients Transplanted in Recent Years. Kidney International 2001; 59: 732-737.

9. Gourishankar S, Jhangri GS, Tonelli M, Wales LH, Cockfield SM. Development of diabetes mellitus following kidney transplantation: A Canadian experience. Am J Transplant. 2004 Nov;4(11):18761882.

10. Jayant TM, Madhumathi R, Victoria J, Selvakumar R, Chakko KJ.Post-Transplant Hyperglycaemia: A Study of Risk Factors. Nephrol Dial Transplant 2003; 18: 164171.

11. Jai P, Surendra SS, Takhellambam BS, Tauhidul AC, Prabhakar, Usha. New onset diabetes after transplantation (NODAT): Analysis of pre-transplant risk factors in renal allograft recipients. Indian Journal of Transplantation 2012; 6 (3): 77-82. http://dx.doi.org/10.1016/j.ijt.2012.07.003.

12. Agarwal DK, Upendra S. Post-Transplant Diabetes Mellitus in Renal Transplant Recipients. Apollo Medicine 2008; 5 (4): 338-344. DOI: http://dx.doi .org/10.1016/S0976-0016(11)60162-2.

13. Saxena S, Dash SC, Guleria S, Mittal R, Agarwal SK, Tiwari SC, et al. Posttransplant diabetes mellitus in live related renal allograft recipients: a single centre experience. J Assoc Physicians India. 1996 Jul;44(7):472, 477-9.

14. Bäckman LA. Post-transplant diabetes mellitus: the last 10 years with tacrolimus.Nephrol Dial Transplant. 2004; 19 (Suppl 6): 13-16.

15. Penfornis A, Kury PS. Immunosuppressive drug-induced diabetes. Diabetes Metab. 2006;32(5):539-546. 
16. Jindal RM, Sidner RA. Post-Transplant Diabetes Mellitus. The Role of Immunosuppression. Drug Saf. 1997; 16(4):242-257.

17. Prasad N, Gurjer D, Bhadauria D, Gupta A, Srivastava A, Kaul A, et al. Is Basiliximab induction, a novel risk factor for new onset diabetes after transplantation for living donor renal allograft recipients?Nephrology (Carlton). 2014; 19(4): 244-250. Doi: 10.1111/nep.12209.

18. Johannes P. Van H, Maarten HL, Christiaans, Elly M. Van D. Evaluating Mechanisms of Post-Transplant Diabetes Mellitus. Nephrol Dial Transplant 2004; 19 [S6]: 8-12, Doi:10.1093/Ndt/Gfh1063.

19. Iida $S$, Ishida $H$, Tokumoto $T$, Omoto $K$, Shirakawa H, Shimizu T, et al. New-onset diabetes after transplantation in tacrolimus-treated, living kidney transplantation: long-term impact and utility of the pre-transplant OGTT. IntUrolNephrol. 2010; 42(4): 935-945. DOI: $10.1007 / \mathrm{s} 11255-010-9712-0$.

20. Yogesh NVR, Georgi A, Varun S, Pooja PR, Milly M, Prethivee N, et al. Is There a Genetic Predisposition to New-Onset Diabetes After Kidney Transplantation? Saudi J Kidney Dis Transpl 2015; 26(6): 1113-1120.

21. Shazia A, Kesiraju S and Sumanlatha. Association of Genetic Risk Factors and Underlying Mechanism in the Development of New-Onset Diabetes after Transplantation. Donnish Journal of Genetics and Molecular Biology 2015; 1(2): 06-15.

22. Lidia G, Daniel A, Raymond V, Steven VL, Marc JA. New-Onset Diabetes After Renal Transplantation. Risk Assessment and Management. Diabetes Care 2012; 35: 181-188.

23. Trond J, Anders H. Emerging treatments for post-transplantation diabetes mellitus. Nature
Reviews Nephrology. 2015; 11: 465-477. doi:10.1038/nrneph.2015.59

24. Debmalya S, Soumava G, Pratik D. A retrospective study evaluating efficacy and safety of Linagliptin in treatment of NODAT (in renal transplant recipients) in a real world setting. Indian Journal of Endocrinology and Metabolism 2013; 17 (Suppl 1): S203-205.

25. Osama G, Nashwa F, Torki AO, Tarek S. New Onset Diabetes after Transplantation [NODAT] Risks Factors Outcome and Possible Role of Diabetes Educators. J NephrolTher 2014, S1: 005. DOI: http://dx.doi.org/10.4172/2161-0959.S1005.

26. Davidson J, Wilkinson AH, Dantal J, Dotta F, Heller $\mathrm{H}$, et al. New-onset diabetes after transplantation: 2003 international consensus guidelines. Transplantation. 2003; 7: SS3-SS24. 